\title{
The perk of writing: How expressive writing reduces depressive symptoms
}

\author{
Efendy Xu', Tara Yen Siang Tan², Hao Wang ${ }^{3}$, Chen Sung Wong ${ }^{4}$, KamYan Chong ${ }^{5}$, \\ Kususanto Ditto Prihadi ${ }^{6}$ \\ 1,2,3,4,5 Department of Psychology, HELP University, Kuala Lumpur, Malaysia \\ ${ }^{6}$ Faculty of Social Science and Liberal Arts, UCSI University, Kuala Lumpur, Malaysia
}

\begin{tabular}{l} 
Article Info \\
\hline Article history: \\
Received Jul 2, 2021 \\
Revised Aug 20, 2021 \\
Accepted Aug 27, 2021 \\
\hline
\end{tabular}

\section{Keywords:}

Expressive writing

Depressive symptoms

Themes of writing

\begin{abstract}
This study aimed to examine types of expressive writing and the underlying themes that will lead to the reduction of depression symptoms. We hypothesized that positive experience writing will significantly reduce depressive symptoms as compared to other types of expressive writing. This study recruited 45 young adults (17 men, 28 women) between 20 and 28 years old to perform online expressive writing for a four-week period and fill in the Patient Health Questionnaire (PHQ-9) before and after the treatment. Our findings suggested that positive expressive writing led to a significantly greater reduction of depressive symptoms as compared to other types of expressive writing. The qualitative analysis showed that there are eight common themes in positive writing that might contribute to the reduction of symptoms: companionship, mattering, gratitude, positive emotions, energetic, motivation, relaxation, and delicious food. Limitations and implications of the findings are discussed.
\end{abstract}

This is an open access article under the CC BY-SA license.

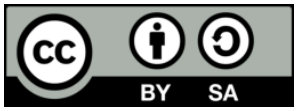

\section{Corresponding Author:}

Efendy $\mathrm{Xu}$

Department of Psychology

Higher Education Learning Philosophy (HELP) University

Selangor, Malaysia

Email: efendyse024@gmail.com

\section{INTRODUCTION}

Depression affects how we feel, think, and act [1]; it is also linked to poor sleep quality [2], alcohol consumption [3], [4] loss of appetite and poor memory [5]. Thirty percent of undergraduate students suffer from depression [2], [6], and in the context of Malaysia, where our study took place, it was reported that the prevalence of depression among university students is considered high [7]. The prevalence was predicted to be increased during the pandemic, as people had to face higher levels of uncertainty [8].

Broaden and Build Theory explained that one of the most signifant protective factors towards depression is positive emotion [9], positive emotions such as joy or contentment broadens an individual's momentary thought-action repertoires, allowing them to obtain personal resources such as social, intellectual, or psychological resources. Such emotions assist people to think more openly, resulting in a broader mindset and widened thought-action repertoire [10], [11], that could help to erase the impact of negative emotions on the mind and body [12]. Positive emotions boost an individual's receptivity to meaning, which increases the likelihood of finding more significance in events and experiencing even more favourable emotions, resulting in an upward spiral [13]-[15]. Thus, improving one's positive emotion might reduce one's depression symptoms, as long as the person has not been diagnosed with clinical depression. Furthermore, positive 
emotions appear to diminish relapses in the treatment of depression by preventing and increasing well-being by developing protective factors such as resilience and coping capacities [16].

One method that has been extensively studied and developed over decade as a therapeutic technique to induce positive emotion is expressive writing [17]. Previous studies have linked writing about positive life experiences to a number of benefits in the general population, including reduced anxiety and stress [18], improved life satisfaction and emotional intelligence and fewer visits to health centres [19]. Additionally, practising expressive writing leads to improved physiological and emotional well-being in both clinical and non-clinical individuals [20], [21]. In the context of Malaysian population, expressive writing, particularly positive experience writing, has been reported to significantly reduce depression symptoms such as melancholy and energy loss [22].

Reviewing previous literature, the vast majority of them were quantitative in nature, examining the effect of expressive writing on different variables. Thereby, it is critical to investigate why and how writing positively can reduce depression, as well as the underlying themes of the writing. This will provide a better understanding of the participants' experiences, helping researchers to develop better writing interventions to reduce or prevent the rate of getting clinical depression. As an answer to that, this study aimed to investigate which types of expressive writing and their underlying themes will negatively affect depression symptoms. As a result, writing about joyful or positive experiences may aid in the reduction of depression or depressive symptoms by reversing negative feelings. Thus, this study was conducted to test a directional hypothesis, whether positive expressive writing significantly reduces depressive symptoms in a more effective way as compared to other types.

\section{RESEARCH METHOD}

\subsection{Design}

A randomized pretest-posttest experimental design was utilized to study the impact of a four-week online expressive writing intervention on depressive symptoms among young adults in Malaysia. Participants were randomly assigned to one of the four conditions, namely, negative experience writing (NEW), positive experience writing (PEW), mixed experience writing (MEW) and best future outcomes writing (BFOW). Participants were then asked to complete the respective expressive writing task twice a week for four weeks.

\subsection{Participants and procedure}

In this study, online research advertising was used as the basis for the recruitment of 45 young adults (17 males, 28 females) between 20 and 28 years old $(\mathrm{M}=22.00, \mathrm{SD}=1.80)$. All participants were not diagnosed with any psychological disorder or participated in any counselling/psychotherapy sessions. They were given eWallet voucher as much as five Ringgit Malaysia to provide their data. The link of the study was shared and posted on researchers' social media platform in the form of posters in order to recruit participants who were interested to participate. Once the data was collected, two analyses were conducted simulataneously, namely quantitative analysis with 4X2 mixed ANOVA method, and thematic analysis to analyse the content of the expressive writing in each group.

\subsection{Materials}

Instructions for Expressive Writing. Participants were guided to perform expressive writing tasks with different writing topics according to the instructions of past research during the four week period [23]-[25]. Participants were asked to reflect and write down their deepest thoughts and feelings without concern about grammatical mistakes. Patient health questionnaire (PHQ-9). The 9-items inventory of PHQ-9 was used to assess the depressive symptoms. The scale was developed based on the nine diagnostic criteria for major depressive disorder in the DSM-IV [26]. This scale has proved to be validated among healthy young adults [27].

\section{RESULTS AND DISCUSSION}

\subsection{Quantitative results}

A 4X2 mixed ANOVA was conducted for the variables of this study. The analysis was conducted to determine whether the interaction between expressive writing and time is significant for the depressive symptoms. Table 1 shows the mean scores for depressive symptoms in the pre- and post-treatment across the groups.

As shown in Table 1, during the pre-treatment, descriptive statistics indicated that PEW (M=9.40, $\mathrm{SD}=2.63)$ has the highest depressive symptoms followed by MEW $(\mathrm{M}=8.80, \mathrm{SD}=5.85), \mathrm{NEW}(\mathrm{M}=7.42$, $\mathrm{SD}=4.32)$, and BFOW (M=7.38, $\mathrm{SD}=5.78)$. During the post-treatment, descriptive statistics showed that PEW has the lowest depressive symptoms $(M=5.60, \mathrm{SD}=2.50)$, followed by $\mathrm{BFOW}(\mathrm{M}=6.23, \mathrm{SD}=3.75)$ and 
NEW (M=7.92, $\mathrm{SD}=3.73)$, while MEW $(\mathrm{M}=9.80, \mathrm{SD}=4.98)$ has the highest depressive symptoms. Table 2 shows the ANOVA results.

Table 1. Mean scores for depressive symptoms during pre- and post-treatment

\begin{tabular}{lccccc}
\hline \multirow{2}{*}{ Expressive writing } & \multicolumn{2}{c}{ Pre-treatment } & \multicolumn{3}{c}{ Post-treatment } \\
& $M$ & $S D$ & $M$ & $S D$ & $n$ \\
\hline PEW & 9.40 & 2.63 & 5.60 & 2.50 & 10 \\
NEW & 7.42 & 4.32 & 7.92 & 3.73 & 12 \\
MEW & 8.80 & 5.84 & 9.80 & 4.98 & 10 \\
BFOW & 7.38 & 5.78 & 6.23 & 3.74 & 13 \\
\hline
\end{tabular}

Table 2. The ANOVA results on the PHQ-9

\begin{tabular}{lcccc}
\hline \multirow{2}{*}{ Expressive writing } & \multicolumn{4}{c}{ Time } \\
& df & F & Sig. & Partial eta squared \\
\hline Between-subjects & & & & \\
Group & 3 & 0.77 & .520 & .05 \\
Error & 41 & & & \\
Within-subjects & & & & \\
Time & 1 & 2.41 & .129 & .06 \\
Error & 41 & & & \\
\hline
\end{tabular}

Table 2 depicts that there was no significant main effect of expressive writing on depressive symptoms, $\mathrm{F}(3,41)=0.77, \mathrm{p}=.520, \eta 2 \mathrm{p}=0.05$ and no significant main effect of time on depressive symptoms, $F(1,41)=2.41, p=.129, \eta 2 p=0.06$. Furthermore, results showed that there was a significant interaction effect between expressive writing and time on depressive symptoms, $F(3,41)=3.49, p=.024, \eta 2 p=0.20$. This indicated that there were significant changes in depressive symptoms from pre- and post-treatment in one of the expressive writing groups. Figure 1 shows the estimated marginal means of expressive writing on depressive symptoms across the time.

Simple main effects analysis using Bonferroni correction indicated that only PEW resulted in significantly lower depressive symptoms in participants from pre- to post-treatment (Mdiff $=3.80, \mathrm{SE}=1.17$, $\mathrm{p}=.002,95 \%$ CI $[1.43,6.17])$; whereas BFOW did not result in significantly lower depressive symptoms (Mdiff $=1.15, \mathrm{SE}=1.03, \mathrm{p}=.269,95 \%$ CI $[-0.92,3.23]$ ). Furthermore, the scores on expressive writing for the NEW and MEW groups actually increased from pre- to post-treatment. However, further analysis showed that both NEW (Mdiff= $-0.50, \mathrm{SE}=1.07, \mathrm{p}=.643,95 \% \mathrm{CI}[-2.66,1.66])$ and MEW (Mdiff=-1.00, SE=1.17, $\mathrm{p}=.399,95 \%$ CI $[-3.37,1.37])$ did not result in significantly changes in depressive symptoms from pre- to post-treatment. Hence, the hypothesis that PEW has significant reduction in depressive symptoms as compared to other writings is supported.

\subsection{Qualitative results and discussion}

Thematic analysis was conducted to analyze the qualitative results. There were eight themes identified in the writings of participants about their prior experiences. This indicated the major source of participants' positive experiences. Tables 3-10 show the themes and its respective samples of the qualitative findings.

Table 3. Companionship

\begin{tabular}{cl}
\hline Theme & Samples \\
\hline Companionship $P 07-$ I had crashed my father's car when I'm driving...At the time, my father replied to me, \\
money is not that important, the important thing is that you weren't injured in that accident. \\
Friends: P08 - I really enjoy spontaneous chat nights with my friends back in university. There were \\
days where we just decided to eat in and hang out in one of our friend's dorm room
\end{tabular}

Previous study suggested that writing about positive experiences could reinforce positive emotions [28]. Writing these experiences could lower participant's depressive symptoms by increasing social connectedness and perceived social support [29], [30]. Perceived mattering usually refers to one's perception of being important to others [31]. Past research has also reported that perceived mattering is negatively associated with depression symptoms [32]. 
Table 4. Mattering

\begin{tabular}{cl}
\hline Theme & Samples \\
\hline \multirow{3}{*}{ Mattering } & Being noticed by others: P07 - I met two to three best friends, I felt being needed when social. I felt \\
& happy as I was being noticed by others. \\
& Being loved: P08 - Knowing that my family had loved me enough to provide such a small celebration \\
& for my born day... I am indeed loved. \\
\hline
\end{tabular}

Table 5. Gratitude

\begin{tabular}{cl}
\hline Theme & Samples \\
\hline Gratitude & $\begin{array}{l}\text { Should just focus on people who loves me. } \\
\text { Blessed: P12 - I feel blessed to have such big and harmonious families. Apart from this, I feel so blessed } \\
\text { that we still remember each other and connected even we are so far apart and busy working }\end{array}$ \\
\hline
\end{tabular}

The previous study has found that gratitude and satisfaction with life are negatively associated with depression symptoms [33]. Gratitude led participants to interpret any life events positively, therefore contrast with characteristics of depression symptoms, which focus more on negative aspects of self, future and life [34]. Writing about past positive emotions would help participants to enhance their positive emotions in the present moment [28], which might buffer the negative effects of lack of positive emotions in depression [35]. Moreover, feeling positive increases the likelihood of ones to seek external support [36].

Table 6. Positive emotions

\begin{tabular}{cl}
\hline Theme & Samples \\
\hline \multirow{3}{*}{ Positive emotions } & favorite toys after a long time. \\
& Cherish: P12 - I was feeling blessed and I really cherish the wonderful moment that we had together. \\
\hline
\end{tabular}

Table 7. Energetic

\begin{tabular}{ll}
\hline Theme & \multicolumn{1}{c}{ Samples } \\
\hline \multirow{2}{*}{ Energetic } & $\begin{array}{l}\text { how hard they were. } \\
\text { Full of energy: P09 - It felt like I was so full of energy, every emotion was so vivid and full. I could brave the cold winter, } \\
\text { cross seas and I was just full of energy and passion! I felt alive. }\end{array}$ \\
\hline
\end{tabular}

Re-experience feelings of excitement, full of energy and experience of being highly concentrated in exciting events could make them more energetic and in turn reduce the depressive feeling of unable to concentrate, lack of interest and no energy of doing things [26]. Experience of achievement and motivation could reinforce one's self-efficacy [37]. Depression is linked with deficits in cognitive control [38], in which having higher self-efficacy could increase personal control [39], thereby reducing the symptoms of depression. Participant's happy memories often came from the moments they felt relaxed. Going through these feelings could calm down a participant's mind. The calming effect of expressive writing could reduce depressive symptoms such as feeling tired and restless, or the tendency of individuals to ruminate [26].

Table 8. Motivation

\begin{tabular}{cl}
\hline Theme & \multicolumn{1}{c}{ Samples } \\
\hline \multirow{3}{*}{ Motivation } & $\begin{array}{l}\text { Achievement: P03 - One of my happiest moment happened recently which is I manage to become one of the Student } \\
\text { Ambassadors in 2021. } \\
\text { Motivated: P07 - I feel that I was being loved in that time. And that sense gives me a motivation to diet and learning. }\end{array}$ \\
\hline
\end{tabular}

Table 9. Relaxation

\begin{tabular}{cl}
\hline Theme & \multicolumn{1}{c}{ Samples } \\
\hline \multirow{3}{*}{ Relaxation } & $\begin{array}{l}\text { Calm: P02 - What the song hit me the most is because I am used to listening to it when I am depressed or give up on } \\
\text { living. By listening to it, it calms my mind. } \\
\text { Peaceful: P06 - It feels like finding peace moment in the world of stress and the feeling is very relaxed and peaceful. }\end{array}$ \\
\hline
\end{tabular}


Table 10. Delicious food

Theme Samples

Delicious Delicious food: P18 - I got my bubble milk tea which I had craving for about 5 months. The feeling of exciting and

food happiness came through... it makes me feeling positive whole day and satisfied with my efforts

One of the depressive symptoms is having poor appetite [26] and this symptom may be reduced after writing about food as snack-related thought has been found to be associated with food cravings [40]. Results showed that people who wrote about positive experiences had much lower depression symptoms than those who did not. Writing about positive experiences is the key to increase positive emotions, improve emotional regulation, control over emotional events as well as self-efficacy [11], [41], [42]. This reappraisal of positive emotions also alters one's subsequent emotional response, and this is associated with higher resiliency [43], and lower susceptibility to clinical depression [44]. Similar benefits might not present in BFOW, as participants were only told to write about imaginative goals, without reliving or rexperiencing positive emotions and thoughts [23]. For NEW and MEW, there might be an increase in negative emotions as participants were asked to include negative events in their writing, thus they are unlikely to experience the psychological benefits provided by positive emotions [35].

\subsection{Limitations}

The language barrier might be one of the limitations of this study. For instance, participants might focus more on how to translate the writings from their native language to English, thus spending less time on the content and re-experiencing the emotions and moments. Future studies are suggested to look into the language barrier and its effects on expressive writing. Moreover, the study can also include criteria for participants to participate by using IELTS band scores for example where participants are required to have moderate English skills (IELTS bands 4-6).

Since this study was conducted online, there was minimal control or monitoriation over the participants' environment. They might perform the writing tasks in a distracting environment. In turn, it will affect their engagement and concentration, particularly during re-experiencing emotions and forming their thoughts. Future researchers are suggested to provide clearer instruction to the participants in which they should perform the writing in a quiet place so they can be fully involved in the process of writing.

\subsection{Implications}

Keeping a diary to record good experiences is an effective and low-cost technique for reducing depressive symptoms in young adults. Another cost-effective way is blogging or posting about it on the web. Future studies could also see whether reading or listening to another individual's positive experiences would influence their well-being. The instructions for expressive writing can also be modified to optimise the beneficial outcomes, tailoring it to everyone's experience or themes that arose in their writing.

\section{CONCLUSION}

This study confirmed that writing about positive experiences can reduce depressive symptoms. Furthermore, we elaborated on how positive expressive writing can reduce depressive symptoms by providing thematic analysis on qualitative research. There were several themes written that emerged from participants' writings, namely, companionship, mattering, gratitude, positive emotions, energetic, motivation, relaxation, and delicious food. The findings of this study can be applied as manuals for effective interventions in reducing depressive symptoms among healthy young adults.

\section{ACKNOWLEDGEMENTS}

This study is funded by Internal research Grant (IRGS\#21-01-001) from Research Management Center of HELP University.

\section{REFERENCES}

[1] American Psychiatric Association, "Diagnostic and Statistical Manual of Mental Disorders (5th ed.)," American Psychiatric Association, 2013.

[2] J. Dinis and M. Bragança, "Quality of Sleep and Depression in College Students: A Systematic Review," Sleep science (Sao Paulo, Brazil), vol. 11, no. 4, pp. 290-301, 2018, doi: 10.5935/1984-0063.20180045.

[3] S. A. Churchill and L. Farrell, "Alcohol and depression: evidence from the 2014 health survey for England," Drug and Alcohol Dependence, vol. 180, pp. 86-92, 2017, doi: 10.1016/j.drugalcdep.2017.08.006. 
[4] E. L. Johannessen, H. W. Andersson, J. H. Bjørngaard, and K. Pape, "Anxiety and depression symptoms and alcohol use among adolescents-a cross sectional study of Norwegian secondary school students," BMC public health, vol. 17, no. 1, pp. 1-9, 2017, doi: 10.1186/s12889-017-4389-2.

[5] W. K. Simmons, K. Burrows, J. A. Avery, K. L. Kerr, A. Taylor, J. Bodurka, W. Potter, T. K. Teague and W. C. Drevets, "Appetite changes reveal depression subgroups with distinct endocrine, metabolic, and immune states," Molecular psychiatry, vol. 25, no. 7, pp. 1457-1468, 2020, doi: 10.1038/s41380-018-0093-6.

[6] A. K. Ibrahim, S. J. Kelly, C. E. Adams e C. Glazebrook, "A systematic review of studies of depression prevalence in university students," Journal of Psychiatric Research, vol. 47, pp. 391-400, 2013, doi: 10.1016/j.jpsychires.2012.11.015.

[7] Y. Kotera, S. H. Tinge S. Neary, "Mental health of Malaysian university students: UK comparison, and relationship between negative mental health attitudes, self-compassion, and resilience," Higher Education, vol. 81, no. 2, pp. 403-419, 2021, doi: 10.1007/s10734-020-00547-w.

[8] L. Flesia, M. Monaro, C. Mazza, V. Fietta, E. Colicino, B. Segatto e P. Roma, "Predicting Perceived Stress Related to the Covid-19 Outbreak through Stable Psychological Traits and Machine Learning Models," JCM, vol 9, no.10, pp. 1-17, 2020, doi: 10.3390/jcm9103350.

[9] B. L. Fredrickson, "The broaden-and-build theory of positive emotions. Philosophical Transactions of the Royal Society of London," Series B: Biological Sciences, vol. 359, no. 1449, pp. 1367-1377, 2004, doi: 10.1098/rstb.2004.1512.

[10] C. J. Leslie-Miller, C. E. Waugh e V. T. Cole, "Coping with COVID-19: The Benefits of Anticipating Future Positive Events and Maintaining Optimism," Frontiers in Psychology, vol. 12, pp. 1-9, 2021, doi: 10.3389/fpsyg.2021.646047.

[11] C. M. Stapleton, H. Zhang e J. S. Berman, "The Event-Specific Benefits of Writing About a Difficult Life Experience," Europe's journal of psychology, vol. 17, no. 1, pp. 53-69, 2021, doi: 10.5964/ejop.2089.

[12] K. A. Leger, S. T. Charles e D. M. Almeida, "Positive emotions experienced on days of stress are associated with less same-day and next-day negative emotion," Affective Science, vol. 1, pp. 20-27, 2019, doi: 10.1007/s42761-01900001-w.

[13] I. Demeyer, A. Sanchez and R. De Raedt, "Older adults' attentional deployment: Differential gaze patterns for different negative mood states," Journal of behavior therapy and experimental psychiatry, vol. 55, pp. 49-56, 2017, doi: 10.1016/j.jbtep.2016.11.012.

[14] E. C. Chang, O. D. Chang, M. Li, Z. Xi, Y. Liu, X. Zhang, X. Wang, Z. Li, M. Zhang, X. Zhang and X. Chen, "Positive emotions, hope, and life satisfaction in Chinese adults: A test of the broaden-and-build model in accounting for subjective well-being in Chinese college students," The Journal of Positive Psychology, vol. 14, no. 6, pp. 829-835, 2019, doi: 10.1080/17439760.2019.1579358.

[15] C. Dimitropoulou and S. Leontopoulou, "A positive psychological intervention to promote well-being in a multicultural school setting in Greece," The European Journal of Counselling Psychology, vol. 6, no. 1, pp. 2017, doi: 10.5964/ejcop.v6i1.141.

[16] M. D. Vara, A. Mira, M. Miragall, A. García-Palacios, C. Botella, M. Gili, P. Riera-Serra, J. García-Campayo, F. Mayoral-Cleries and R. M. Baños, "A Low-Intensity Internet-Based Intervention Focused on the Promotion of Positive Affect for the Treatment of Depression in Spanish Primary Care: Secondary Analysis of a Randomized Controlled Trial," International journal of environmental research and public health, vol. 17, no. 21, pp. 1-21, 2020, doi: 10.3390/ijerph17218094.

[17] J. T. Moskowitz, E. O. Cheung, K. E. Snowberg, A. Verstaen, J. Merrilees, J. M. Salsman e G. A. Dowling, "Randomized controlled trial of a facilitated online positive emotion regulation intervention for dementia caregivers," Health Psychology, vol. 38, no. 5, pp. 391-402, 2019, doi: 10.1037/hea0000680.

[18] M. A. Smith, Thompson, H. L. J. A., S. F. Allen e M. A. Wetherell, "The physical and psychological health benefits of positive emotional writing: Investigating the moderating role of Type D (distressed) personality," British journal of health psychology, vol. 23, no. 4, pp. 857-871, 2018, doi: 10.1111/bjhp.12320.

[19] Y. A. Castillo, J. Fischer and S. Davila, "Managing emotions: Relationships among expressive writing and emotional intelligence," Integrated Research Advances, vol. 6, no. 1, pp. 1-8, 2019.

[20] D. Arigo and J. M. Smyth, "The benefits of expressive writing on sleep difficulty and appearance concerns for college women," Psychology \& Health, vol. 27, no. 2, pp. 210-226, 2012, doi: 10.1080/08870446.2011.558196.

[21] K. A. Baikie, L. Geerligs, and K. Wilhelm, "Expressive writing and positive writing for participants with mood disorders: An online randomized controlled trial," Journal of affective disorders, vol. 136, no. 3, pp. 310-319, 2012, doi: 10.1016/j.jad.2011.11.032.

[22] C. S. Wong, M. J. Chua, and K. D. Prihadi, "Reducing depressive symptoms and increasing positive feelings with expressive writing," International Journal of Public Health Science (IJPHS), vol. 10, no. 2, pp. 433-444, 2021, doi: 10.11591/ijphs.v10i2.20797.

[23] P. M. Loveday, G. P. Lovell, and C. M. Jones, "The best possible selves intervention: A review of the literature to evaluate efficacy and guide future research," Journal of Happiness Studies, vol. 19, no. 2, pp. 607-628, 2018, doi: 10.1007/s10902-016-9824-z.

[24] J. Quoidbach, M. Mikolajczak, and J. J. Gross, "Positive interventions: An emotion regulation perspective," Psychological Bulletin, vol. 141, no. 3, pp. 655- 693, 2015, doi: 10.1037/a0038648.

[25] M. Reinhold, P. C. Bürkner, and H. Holling, "Effects of expressive writing on depressive symptoms-A metaanalysis," Clinical Psychology: Science and Practice, vol. 25, no. 1, 2018, doi: 10.1111/cpsp.12224. 
[26] K. Kroenke, R. L. Spitzer, and J. B. Williams, "The PHQ-9: validity of a brief depression severity measure," Journal of General Internal Medicine, vol. 16, no. 9, pp. 606-613, 2001, doi: https://doi.org/10.1046/j.15251497.2001.016009606.x.

[27] B. T. Keum, M. J. Miller, and K. K. Inkelas, "Testing the factor structure and measurement invariance of the PHQ9 across racially diverse US college students," Psychological Assessment, vol. 30, no. 8, pp. 1096-1106, 2018, doi: 10.1037/pas0000550.

[28] M. Suhr, A. K. Risch, and G. Wilz, "Maintaining mental health through positive writing: Effects of a resource diary on depression and emotion regulation," Journal of clinical psychology, vol. 73, no. 12, pp. 1586-1598, 2017, doi: $10.1002 / j \mathrm{jclp} .22463$.

[29] A.-M. Creaven, A. Healy, and S. Howard, "Social connectedness and depression: Is there added value in volunteering?," Journal of Social and Personal Relationships, vol. 35, no. 10, pp. 1400-1417, 2018, doi: $10.1177 \% 2 \mathrm{~F} 0265407517716786$.

[30] D. E. Eagle, C. F. Hybels, and R. J. Proeschold-Bell, "Perceived social support, received social support, and depression among clergy," Journal of Social and Personal Relationships, vol. 36, no. 7, pp. 2055-2073, 2019, doi: $10.1177 \% 2 F 0265407518776134$.

[31] S. K. Marshall, "Do I matter? Construct validation of adolescents' perceived mattering to parents and friends," Journal of adolescence, vol. 24, no. 4, pp. 473-490, 2001, doi: 10.1006/jado.2001.0384.

[32] K. D. Prihadi, C. Y. Wong, E. Y. Chong, and K. Y. Chong, "Suicidal thoughts among university students: The role of mattering, state self-esteem and depression level," International Journal of Evaluation and Research in Education (IJERE), vol. 9, no. 3, pp. 494-502, 2020, doi: 10.11591/ijere.v9i3.20587.

[33] E. C. McCanlies, J. K. Gu, M. E. Andrew, and J. M. Violanti, "The effect of social support, gratitude, resilience and satisfaction with life on depressive symptoms among police officers following Hurricane Katrina," International Journal of Social Psychiatry, vol. 64, no. 1, pp. 63-72, 2018, doi: 10.1177\%2F0020764017746197

[34] L. Wood, K. Martin, H. Christian, A. Nathan, C. Lauritsen, S. Houghton, I. Kawachi and S. McCune, "The pet factor-companion animals as a conduit for getting to know people, friendship formation and social support," PloS one, vol. 10, no. 4, 2015, doi: 10.1371/journal.pone.0122085.

[35] T. Beblo, S. Fernando, S. Klocke, J. Griepenstroh, S. Aschenbrenner, and M. Driessen, "Increased suppression of negative and positive emotions in major depression. Journal of affective disorders," Journal of affective disorders, vol. 141, no. 2-3, pp. 474-479, 2012, doi: 10.1016/j.jad.2012.03.019.

[36] S. A. Hussain and S. Alhabash, "Effect of nostalgia as a motivational force for depressed students to seek professional psychological help," Journal of American College Health, pp. 1-9, 2020, doi: $10.1080 / 07448481.2020 .1754838$

[37] L. R. Zientek, C. J. Fong and J. M. Phelps, "Sources of self-efficacy of community college students enrolled in developmental mathematics," Journal of Further and Higher Education, vol. 43, no. 2, pp. 183-200, 2019, doi: 10.1080/0309877X.2017.1357071.

[38] J. LeMoult and I. H. Gotlib, "Depression: A cognitive perspective," Clinical Psychology Review, vol. 69, pp. 51-66, 2019, doi: 10.1016/j.cpr.2018.06.008.

[39] I. Grahek, A. Shenhav, S. Musslick, R. M. Krebs, and E. H. Koster, "Motivation and cognitive control in depression," Neuroscience \& Biobehavioral Reviews, vol. 102, pp. 371-381, 2019, doi: 10.1016\%2Fj.neubiorev.2019.04.011.

[40] A. Richard, A. Meule, J. Reichenberger, and J. Blechert, "Food cravings in everyday life: An EMA study on snackrelated thoughts, cravings, and consumption," Appetite, vol. 113, pp. 215-223, 2017, doi: 10.1016/j.appet.2017.02.037.

[41] N. Kupeli, G. Chatzitheodorou, N. A. Troop, D. McInnerney, P. Stone, and B. Candy, "Expressive writing as a therapeutic intervention for people with advanced disease: a systematic review," BMC Palliative Care, vol. 18, no. 1, 2019, doi: 10.1186/s12904-019-0449-y.

[42] S. Duan, M. Exter, T. Newby, and F. Bingxin, "No Impact? Long-Term Effects of Applying the Best Possible Self Intervention in a Real-World Undergraduate Classroom Setting," International Journal of Community Well-Being, 2021, doi: 10.1007/s42413-021-00120-y.

[43] J. M. Painter, J. Mote, A. D. Peckham, E. H. Lee, T. R. Campellone, J. G. Pearlstein, S. Morgan, A. M. Kring, S. L. Johnson, and J. T. Moskowitz, "A positive emotion regulation intervention for bipolar I disorder: Treatment development and initial outcomes," General Hospital Psychiatry, vol. 61, p. 96-103, 2019, doi: 10.1016/j.genhosppsych.2019.07.013.

[44] A. A. Contractor, A. N. Banducci, L. Jin, F. S. Keegan e N. H. Weiss, "Effects of processing positive memories on posttrauma mental health: A preliminary study in a non-clinical student sample," Journal of Behavior Therapy and Experimental Psychiatry, vol. 66, 2020, doi: 10.1016/j.jbtep.2019.101516. 